\title{
PERAMALAN KEBUTUHAN DAYA LISTRIK MENGGUNAKAN MODEL ARIMA DAN FUNGSI TRANSFER (STUDI KASUS: PT. PLN (PERSERO) AREA SUMBAWA)
}

\author{
Mikhratunnisa $^{1}$, Tri Susilawati ${ }^{2}$ \\ Universitas Teknologi Sumbawa ${ }^{1}$, mikhratunnisa@uts.ac.id ${ }^{1}$ \\ Universitas Teknologi Sumbawa², tri.susilawati@uts.ac.id²
}

DOI:https://doi.org/10.15642/mantik.2018.4.1.122-127

\begin{abstract}
Abstrak
Energi adalah salah satu kebutuhan dasar manusia. Salah satu sumber energi yang paling vital adalah energi listrik. Kebutuhan listrik di Nusa Tenggara Barat (NTB) terus meningkat dari tahun ke tahun seiring dengan perkembangan penduduk dan perekonomian NTB, khususnya di Kabupaten Sumbawa. Untuk memenuhi kebutuhan pelanggan akan energi listrik, maka dibutuhkan penyediaan dan penyaluran kebutuhan energi listrik yang memadai. Oleh karena itu, diperlukan suatu cara yang tepat dalam penyesuain jumlah kapasitas listrik agar sesuai dengan permintaan pelanggan. Salah satu cara yang dapat dilakukan adalah meramalkan/memprediksi kebutuhan daya listrik. Peramalan dapat dilakukan dengan menggunakan model ARIMA dan Fungsi Transfer. Hasil penelitian menunjukkan bahwa dengan menggunakan model ARIMA diperkirakan kebutuhan daya listrik pada tahun 2018 mengalami peningkatan sebesar 18,21\% dari satu tahun sebelumnya, sedangkan menggunakan model fungsi transfer diperkirakan mengalami peningkatan sebesar $18,18 \%$ dari satu tahun sebelumnya.
\end{abstract}

Kata kunci: daya listrik, ARIMA, fungsi transfer

\begin{abstract}
Energy is one of the basic need of human being. One of the vital energy is electricity. The need of electricity in NTB is increase along with the citizen economic development in NTB especially in Sumbawa regency. Therefore, there is a need for the right way in adjusting the amount of electrical capacity to match customer demand. One way that can be done is to forecast/ predict the need for electricity. The forecast can be used by using the ARIMA and Transfer Function models. The results of the study show that using the ARIMA model is estimated to require electricity in 2018 experienced an increase of $18,21 \%$ from the previous year, while using the transfer function model is estimated to increase by $18,18 \%$ from the previous year.
\end{abstract}

Key words: Electricity power, ARIMA, transfer function

\section{Pendahuluan}

Energi adalah salah satu kebutuhan dasar manusia. Salah satu sumber energi yang paling vital adalah energi listrik. Listrik adalah jenis energi yang menopang kelangsungan hidup manusia, khususnya di sektor industri [1]. Energi listrik merupakan salah satu kebutuhan masyarakat yang sangat penting dan sebagai sumber daya ekonomis yang paling utama yang dibutuhkan dalam berbagai kegiatan. Dalam waktu yang akan datang kebutuhan listrik akan terus meningkat seiring dengan adanya peningkatan dan perkembangan baik dari jumlah penduduk, jumlah investasi, dan perkembangan teknologi [2].

Kabupaten Sumbawa adalah salah satu Kabupaten/Kota di Provinsi Nusa Tenggara Barat (NTB) yang terletak di pulau Sumbawa. Kebutuhan listrik di Nusa Tenggara Barat (NTB) terus meningkat dari tahun ke tahun seiring dengan perkembangan penduduk dan 


\section{JURNAL MATEMATIKA "MANTIK" \\ Oktober 2018. Vol. 04 No. 02}

perekonomian NTB, khususnya di Kabupaten Sumbawa [3]. Untuk memenuhi kebutuhan pelanggan akan energi listrik, maka dibutuhkan penyediaan dan penyaluran energi listrik yang memadai baik dari segi teknis maupun ekonomisnya. Oleh karena itu, diperlukan suatu cara yang tepat dalam penyesuaian jumlah kapasitas listrik agar sesuai dengan permintaan pelanggan. Salah satu cara yang dapat dilakukan adalah meramalkan/memprediksi kebutuhan daya listrik, yakni dengan menggunakan model ARIMA dan model Fungsi transfer. Model ARIMA merupakan salah satu model time series yang populer dan banyak digunakan. Model ARIMA adalah model time series univariat, sedangkan fungsi transfer merupakan model time series multivariat. Model ARIMA hanya menghubungkan time series berdasarkan nilainilai sebelumnya dari time series tersebut. Pada model fungsi transfer, selain menghubungkan suatu time series dengan nilai-nilai sebelumnya dari time series tersebut, juga menghubungkan suatu time series dengan time series lainnya [4]. Sehingga dengan penelitian ini diharapkan mendapatkan model yang sesuai untuk meramalkan/memprediksi kebutuhan daya listrik pada periode yang akan datang.

\section{Tinjauan Pustaka}

\subsection{Model ARIMA}

Model ARIMA $(p, d, q)$ merupakan gabungan dari model $\operatorname{AR}(p)$ dan MA $(q)$, dengan pola data non stasioner dan differencing orde $d$. Bentuk model ARIMA $(p, d, q)$ sebagai berikut [5]:

$$
\phi_{p}(B)(1-B)^{d} Y_{t}=\theta_{q}(B) a_{t}
$$

dimana $p$ adalah orde dari model AR, $q$ adalah orde dari model MA, $d$ adalah orde differencing, dan

$$
\begin{aligned}
& \phi_{p}(B)=\left(1-\phi_{1} B-\phi_{2} B^{2}-\ldots-\phi_{p} B^{p}\right) \\
& \theta_{q}(B)=\left(1-\theta_{1} B-\theta_{2} B^{2}-\ldots-\theta_{q} B^{q}\right)
\end{aligned}
$$

Generalisasi model ARMA untuk pola data musiman ditulis sebagai ARIMA $(p, d, q)(P, D, Q)^{\mathrm{s}}$, yaitu

$\phi_{p}(B) \Phi_{P}\left(B^{s}\right)(1-B)^{d}\left(1-B^{s}\right)^{D} Y_{t}=\theta_{q}(B) \Theta_{Q}\left(B^{s}\right) a_{t}$ dimana $s$ adalah periode musiman,

$$
\begin{aligned}
& \Phi_{P}\left(B^{s}\right)=\left(1-\Phi_{1} B^{s}-\Phi_{2} B^{2 s}-\ldots-\Phi_{P} B^{P s}\right) \\
& \Theta_{Q}\left(B^{s}\right)=\left(1-\Theta_{1} B^{s}-\Theta_{2} B^{2 s}-\ldots-\Theta_{Q} B^{Q s}\right)
\end{aligned}
$$

Model ARIMA memiliki beberapa asumsi residual yang harus dipenuhi. Pengujian asumsi sering disebut diagnostic checking. Asumsi tersebut adalah residual bersifat white noise dan berdistribusi normal. Model ARIMA yang telah memenuhi asumsi tersebut diklasifikasikan sebagai model yang baik [5]. Karakteristik model AR, MA, dan ARMA berdasarkan plot ACF dan

\begin{tabular}{|c|c|c|}
\hline Proses & $\mathrm{ACF}$ & PACF \\
\hline $\operatorname{AR}(p)$ & $\begin{array}{l}\text { Dies down } \\
\text { secara } \\
\text { eksponensial } \\
\text { atau } \\
\text { sinusoidal }\end{array}$ & $\begin{array}{l}\text { Cut off pada } \\
\text { lag ke-p }\end{array}$ \\
\hline $\operatorname{MA}(q)$ & $\begin{array}{l}\text { Cut off pada } \\
\text { lag ke- } q\end{array}$ & $\begin{array}{l}\text { Dies down } \\
\text { secara } \\
\text { eksponensial } \\
\text { atau } \\
\text { sinusoidal } \\
\end{array}$ \\
\hline $\begin{array}{l}\operatorname{ARMA}(p, \\
q)\end{array}$ & $\begin{array}{l}\text { Dies down } \\
\text { secara } \\
\text { eksponensial } \\
\text { atau } \\
\text { sinusoidal }\end{array}$ & $\begin{array}{l}\text { Dies down } \\
\text { secara } \\
\text { eksponensial } \\
\text { atau } \\
\text { sinusoidal }\end{array}$ \\
\hline
\end{tabular}
PACF dari data yang telah stasioner sebagai berikut.

Tabel 1. Karakteristik ACF dan PACF untuk Proses Stasioner

\subsection{Model Fungsi Transfer}

Bentuk umum model fungsi transfer single input (model fungsi transfer dengan satu variabel input) sebagai berikut [6].

$$
Y_{t}=c+v(B) X_{t}+N_{t}
$$

dimana

$$
\begin{aligned}
& v(B)=\frac{\omega_{s}(B)}{\delta_{r}(B)} B^{b} \\
& N_{t}=\frac{\theta(B)}{\phi(B)} a_{t} \\
& \omega_{s}(B)=\omega_{0}+\omega_{1} B+\omega_{2} B^{2}+\ldots+\omega_{s} B^{s} \\
& \delta_{r}(B)=1+\delta_{1} B+\delta_{2} B^{2}+\ldots+\delta_{r} B^{r} \\
& \theta(B)=1-\theta_{1} B-\theta_{1} B^{2}-\ldots-\theta_{q} B^{q} \\
& \phi(B)=1-\phi_{1} B-\phi_{1} B^{2}-\ldots-\phi_{p} B^{p}
\end{aligned}
$$

Sehingga model fungsi transfer single input ditulis sebagai berikut

$$
Y_{t}=c+\frac{\omega_{s}(B)}{\delta_{r}(B)} B^{b} X_{t}+\frac{\theta(B)}{\phi(B)} a_{t}
$$




\section{Metode Penelitian}

Adapun tahapan peramalan menggunakan model ARIMA yaitu identifikasi model ARIMA, estimasi dan pengujian signifikasi parameter model ARIMA, diagnostic checking, dan peramalan.

Adapun tahapan peramalan menggunakan model fungsi transfer sebagai berikut:

a. Persiapan deret input dan output

b. Prewhitening deret input dan output

c. Perhitungan korelasi silang deret input dan output yang telah melalui proses prewhitening

d. Penentuan orde b, r, s model fungsi transfer

e. Perhitungan bobot respon impuls

f. Penentuan model deret noise

g. Estimasi parameter model fungsi transfer

h. Diagnostic checking model fungsi transfer

i. Peramalan

Data yang digunakan dalam penelitian ini adalah data sekunder yang diperoleh dari PT. PLN (Persero) Area Sumbawa. Data yang digunakan dalam penelitian ini adalah data penggunaan daya listrik dan jumlah pelanggan PLN bulan November 2012 - Desember 2017.

\section{Hasil dan Pembahasan}

Data yang digunakan dalam peramalan menggunakan model ARIMA adalah data penggunaan daya listrik. Tahap awal pada identifikasi model ARIMA yaitu pemeriksaan stasioneritas data baik dalam mean maupun varians. Data penggunaan daya listrik bulan November 2012 - Desember 2017 diperlihatkan pada plot time series berikut.

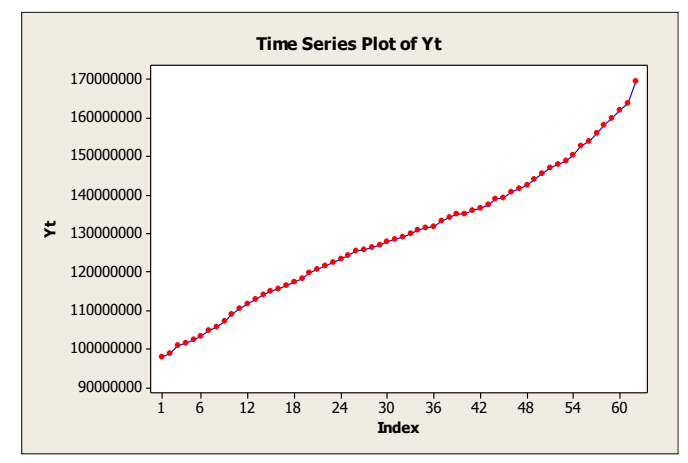

Gambar 1. Plot time series daya listrik

Gambar 1 menujukkan bahwa data belum stasioner dalam mean karena adanya pola trend, sehingga diperlukan proses differencing. Sebelum dilakukan proses differencing, perlu dilakukan pemeriksaan stasioneritas data dalam varian.

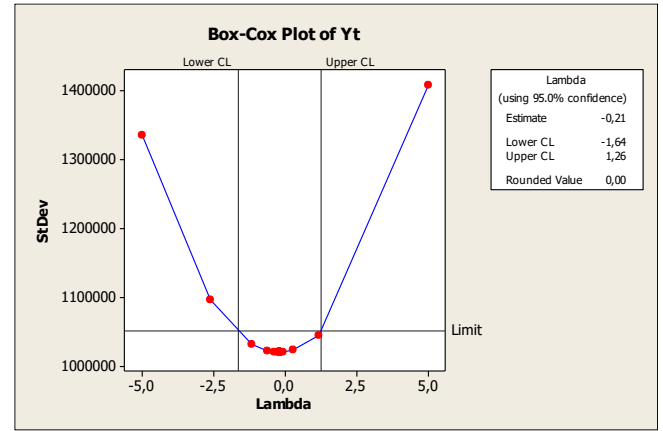

Gambar 2. Transformasi box-cox data daya listrik

Hasil pemeriksaan stasioneritas data dalam varians menggunakan transformasi box-cox (Gambar 2) menunjukkan bahwa data belum stasioner dalam varians, hal ini dapat dilihat pada rounded value sebesar 0,00 . Sehingga perlu dilakukan transformasi agar data menjadi stasioner dalam varians. Transformasi yang sesuai adalah transformasi $\ln$. Selanjutnya dilakukan proses differencing agar data stasioner dalam mean. Proses differencing yang sesuai adalah differencing orde-2. Berikut plot time series setelah transformasi dan differencing.

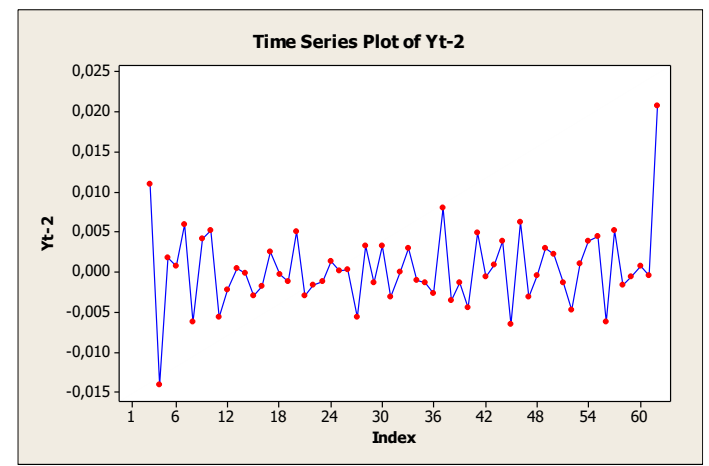

Gambar 3. Plot time series daya listrik $(\mathrm{d}=2)$

Gambar 3 menunjukkan bahwa data telah stasioner dalam mean. Pengujian stasioneritas dalam mean dapat dilakukan dengan menggunakan uji Augmented Dickey-Fuller Unit Root. Hasil pengujian sebagai berikut. 


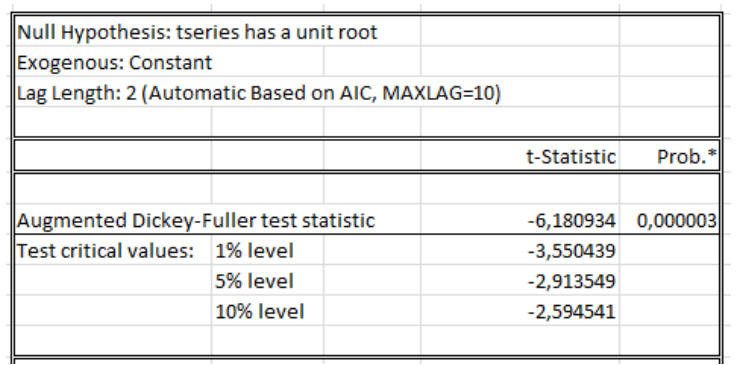

Gambar 4. Uji Augmented Dickey-Fuller Unit Root

Gambar 4 menunjukkan bahwa data telah stasioner dalam mean, karena memiliki p-value < $\alpha(\alpha=5 \%)$. Selanjutnya adalah membentukan model ARIMA berdasarkan plot ACF dan PACF.

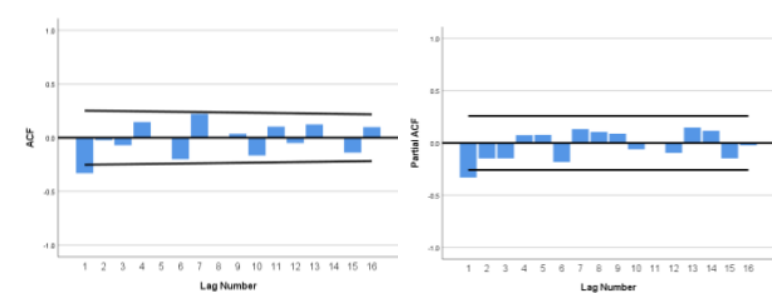

Gambar 5. Plot ACF dan PACF daya listrik $(d=2)$

Berdasarkan Gambar 5 diduga beberapa model ARIMA yang terbentuk yaitu ARIMA $(1,2,0)$, ARIMA $(0,2,1)$ dan ARIMA $(1,2,1)$. Kemudian dilakukan estimasi parameter dan pengujian signifikansi parameter dari model tersebut.

Tabel 2. Hasil estimasi parameter dan pengujian signifikansi parameter model

\begin{tabular}{|c|c|c|c|}
\hline Model & Parameter & Estimasi & $p$-value \\
\hline $\begin{array}{c}\text { ARIMA } \\
(1,2,0)\end{array}$ & $\phi_{1}$ & $-0,524$ & 0,000 \\
\hline $\begin{array}{l}\text { ARIMA } \\
(0,2,1)\end{array}$ & $\theta_{1}$ & 0,699 & 0,000 \\
\hline $\begin{array}{c}\text { ARIMA } \\
(1,2,1)\end{array}$ & $\begin{array}{c}\phi_{1} \\
\theta_{1}\end{array}$ & $\begin{array}{c}-0,149 \\
0,627\end{array}$ & $\begin{array}{l}0,534 \\
0,004\end{array}$ \\
\hline
\end{tabular}

$\alpha=5 \%$

Berdasarkan pengujian signifikansi parameter model diperoleh bahwa parameter model ARIMA $(1,2,0)$ dan ARIMA $(0,2,1)$ signifikan. Kemudian dilakukan diagnostic checking terhadap model tersebut. Hasil diagnostic checking diperoleh bahwa model ARIMA $(0,2,1)$ telah memenuhi asumsi residual white noise. Maka model ARIMA $(0,2,1)$ merupakan model terbaik. Model ARIMA $(0,2,1)$ dapat ditulis sebagai berikut:

$$
(1-B)^{2} Y_{t}^{*}=\left(1-\theta_{1} B\right) a_{t}
$$

$$
Y_{t}^{*}=2 Y_{t-1}^{*}-Y_{t-2}^{*}+a_{t}-0,699 a_{t-1}
$$

dimana $Y_{t}^{*}=\ln Y_{t}$

kemudian dilakukan peramalan kebutuhan daya listrik tahun 2018 menggunakan model ARIMA $(0,2,1)$, dengan hasil peramalan sebagai berikut:

Tabel 3. Hasil peramalan 12 bulan kedepan

\begin{tabular}{ll}
\hline Bulan & Peramalan \\
\hline Januari 2018 & 172446914 \\
Februari 2018 & 175543951 \\
Maret 2018 & 178696608 \\
April 2018 & 181924077 \\
Mei 2018 & 185191318 \\
Juni 2018 & 188517236 \\
Juli 2018 & 191922077 \\
Agustus 2018 & 195368876 \\
September 2018 & 198877577 \\
Oktober 2018 & 202469537 \\
November 2018 & 206105761 \\
Desember 2018 & 209807290 \\
\hline
\end{tabular}

Berdasarkan hasil peramalan menggunakan model ARIMA bahwa kebutuhan daya listrik pada tahun 2018 diperkirakan mengalami peningkatan yakni sebesar $18,21 \%$ dari satu tahun sebelumnya.

Selanjutnya dilakukan peramalan menggunakan model fungsi transfer. Data yang digunakan dalam peramalan kebutuhan daya listrik menggunakan model fungsi transfer yaitu data penggunaan daya listrik sebagai deret output (Y) dan jumlah pelanggan PLN sebagai deret input (X). Tahap awal dalam identifikasi model fungsi transfer yaitu mempersiapkan deret input dan output, dalam hal ini ditentukan model ARIMA deret input dan output.

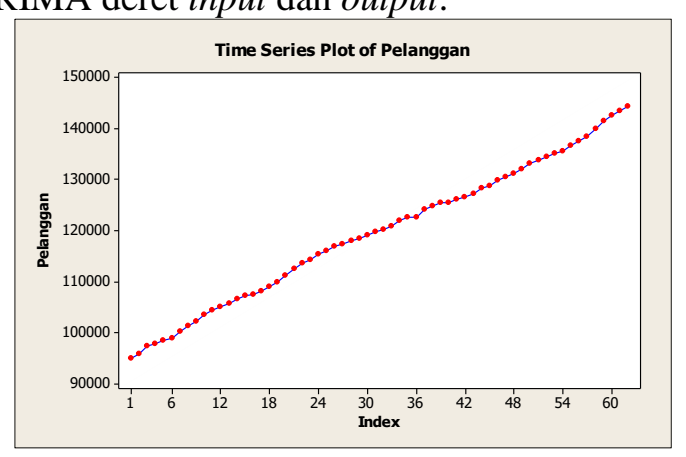

Gambar 6. Plot time series deret input

Berdasarkan plot time series pada Gambar 6 diperoleh bahwa data deret input belum stasioner. 
Sehingga diperlukan proses differencing agar data menjadi stasioner. Hasil differencing yang sesuai yaitu differencing orde- 2 .

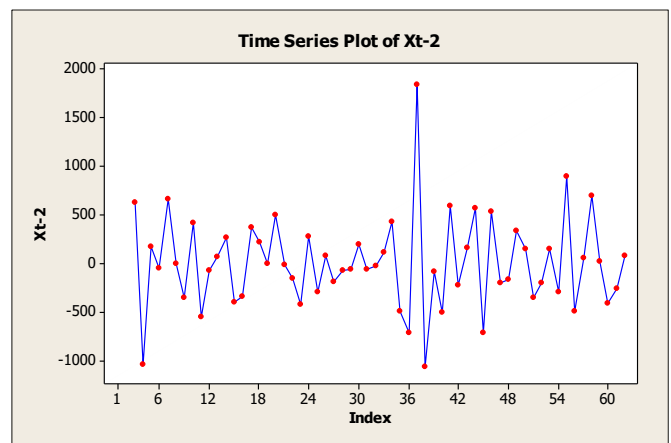

Gambar 7. Plot time series deret input $(\mathrm{d}=2)$

Kemudian dilakukan pemodelan ARIMA deret input berdasarkan plot ACF dan PACF, diperoleh beberapa kemungkinan model yang terbentuk yaitu ARIMA $(0,2,1)$, ARIMA $(1,2,0)$, ARIMA $(2,2,0)$, ARIMA $(1,2,1)$ dan ARIMA $(2,2,1)$. Berdasarkan hasil pengujian signifikasi parameter model dan diagnostic checking diperoleh model terbaik yaitu model ARIMA $(0,2,1)$ karena telah memenuhi asumsi residual white noise dan beridistribusi normal. Selanjutanya dilakukan prewhitening deret input dan output. Hasil Prewhitening deret input dan output dengan model ARIMA $(0,2,1)$ sebagai berikut.

$\alpha_{t}=x_{t}+0,880 \alpha_{t-1}$ dan $\beta_{t}=y_{t}+0,880 \beta_{t-1}$

dimana $x_{t}$ dan $y_{t}$ adalah hasil differencing dari $X_{t}$ dan $Y_{t}$.

Selanjutnya penentuan orde $b, r$ dan $s$ model fungsi transfer berdasarkan plot korelasi silang antara deret input dan output yang telah melalui proses prewhitening, diperoleh orde $b=0, r=0$, dan $s=0$. Kemudian dilakukan pehitungan bobot respon impuls dan identifikasi model ARIMA deret noise. Diperoleh model deret noise yang sesuai dan telah memenuhi asumsi (white noise dan berdistribusi normal) yaitu model ARIMA $(1,1,0)$. Berdasarkan orde $b, r, s$ dan model deret noise diperoleh model fungsi transfer sebagai berikut

$$
\begin{gathered}
y_{t}=y_{t-1}+\phi_{1}\left(y_{t-1}-y_{t-2}\right)+\omega_{0}\left(x_{t}-x_{t-1}\right)- \\
\phi_{1} \omega_{0}\left(x_{t-1}-x_{t-2}\right)+a_{t}
\end{gathered}
$$

Model yang diperoleh tersebut sudah sesuai dan dapat digunakan untuk peramalan, karena parameter model telah signifikan dan memenuhi asumsi white noise (uji korelasi silang dan uji autokorelasi). Sehingga model tersebut dapat ditulis sebagai berikut

$$
\begin{aligned}
y_{t}= & y_{t-1}-0,614\left(y_{t-1}-y_{t-2}\right)+603,805\left(x_{t}-x_{t-1}\right)- \\
& 370,736\left(x_{t-1}-x_{t-2}\right)+a_{t}
\end{aligned}
$$

Hasil peramalan kebutuhan daya listrik tahun 2018 menggunakan model fungsi transfer sebagai berikut.

Tabel 4. Hasil peramalan 12 bulan kedepan

\begin{tabular}{lc}
\hline Bulan & Ramalan \\
\hline Januari & 171213124 \\
Februari & 176541333 \\
Maret & 178226054 \\
April & 183428947 \\
Mei & 184993329 \\
Juni & 190083038 \\
Juli & 191538613 \\
Agustus & 196526103 \\
September & 197883293 \\
Oktober & 202778470 \\
November & 204046694 \\
Desember & 208858512 \\
\hline
\end{tabular}

Berdasarkan hasil peramalan menggunakan model model fungsi transfer bahwa kebutuhan daya listrik pada tahun 2018 diperkirakan mengalami peningkatan yakni sebesar 18,18\% dari satu tahun sebelumnya.

\section{Kesimpulan}

Berdasarkan hasil penelitian diperoleh bahwa dengan menggunakan model ARIMA diperkirakan kebutuhan daya listrik pada tahun 2018 mengalami peningkatansebesar $18,21 \%$ dari satu tahun sebelumnya. Sedangkan menggunakan fungsi transfer diperkirakan kebutuhan daya listrik mengalami peningkatan sebesar $18,18 \%$ dari satu tahun sebelumnya. 


\section{Referensi}

[1] Alfita, R., Mamluah, D., Ulum, M., Nahari, R.V, Implementation of Fuzzy Sugeno Method for Power Efficiency, International Journal of Advanced Engineering Research and Science (IJAERS). Vol. 4. No. 9. (2017) 1-5.

[2] Wahid, A., Junaidi., Arsyad, M.I, Analisis Kapasistas dan Kebutuhan Daya Listrik Untuk Menghemat Penggunaan Energi Listrik di Fakultas Teknik Universitas Tanjungpura. Jurnal Teknik Elektro Universitas Tanjungoura. Vol 2, No 1. (2014).

[3] Bappeda, "Nusa Tenggara Barat Dalam Angka 2012", Penerbit Katalog BPS, Provinsi NTB, (2012).

[4] Arumugam, P. and Anithakumari, V, Seasonal Time Series and Transfer Function Modelling for Natural Rubber Forecasting in India. International Journal of Computer Trends and Technology (IJCTT). Vol. 4. No. 5. (2013) 13661370.

[5] Wei, W.W.S, Time Series Analysis: Univariate and Multivariate Method. Canada. AddisonWesley Pub. Inc. (2006).

[6] Liu, L.M. Time series Analysis and Forecasting. Scientific Computing Associates Corp. (2006). 